University of Nebraska - Lincoln

DigitalCommons@University of Nebraska - Lincoln

Kenneth Nickerson Papers

Papers in the Biological Sciences

2009

Microbiology of Oil Fly Larvae

Kenneth Nickerson

Bradley A. Plantz

Follow this and additional works at: https://digitalcommons.unl.edu/bioscinickerson

Part of the Environmental Microbiology and Microbial Ecology Commons, Other Life Sciences Commons, and the Pathogenic Microbiology Commons

This Article is brought to you for free and open access by the Papers in the Biological Sciences at DigitalCommons@University of Nebraska - Lincoln. It has been accepted for inclusion in Kenneth Nickerson Papers by an authorized administrator of DigitalCommons@University of Nebraska - Lincoln. 


\title{
Microbiology of Oil Fly Larvae
}

\author{
K. W. Nickerson and B. Plantz
}

School of Biological Sciences, University of Nebraska-Lincoln, Lincoln, NE, USA

\begin{abstract}
One animal beautifully adapted to the viscous asphalt of the La Brea tar pits is the oil fly Helaeomyia petrolei (Syn. Psilopa). As a normal part of its carnivorous existence the oil fly larval guts are filled with tar, with no adverse effects. Surface sterilized larvae 5 contained ca. 2 x 10 heterotrophic bacteria per larva. These bacteria have been identified as a mixture of enteric bacteria, most commonly Providencia rettgeri, and Acinetobacter spp. These bacteria were clearly growing because their numbers in the larval guts were 100 to 1,000 times greater than in free oil/asphalt. There is no evidence yet that these bacteria can degrade the complex aromatic hydrocarbons of the tar/asphalt. However, the bacteria isolated are highly solvent tolerant and they remain a potential source of hydrocarbon/solvent tolerant enzymes. Likely of greatest evolutionary interest, these bacteria were naturally resistant to 9 of 23 common antibiotics tested. This finding suggests that the oil fly bacteria have an active efflux pump for aromatic hydrocarbons, due to the constant selective pressure of La Brea's solvent-rich environment. We suggest that the oil fly bacteria and their genes for solvent tolerance may provide a microbial reservoir for antibiotic resistance genes.
\end{abstract}

\section{Introduction}

When the La Brea tar pits are mentioned in conversation most people visualize a highly viscous petroleum quicksand, with the consistency of roofing tar on a hot day. For any animal unfortunate enough

\footnotetext{
Published in Timmis, Kenneth N. (ed.) Handbook of Hydrocarbon and Lipid Microbiology (Heidelberg: Springer, 2009) v 2, pp 1625-1633.

DOI:10.1007/978-3-540-77587-4_114

Copyright (c) 2010 Springer-Verlag Berlin Heidelberg. Used by Permission.
} 
to fall into these tar pits, it is a one-way trip. This view is usually based on the discovery in the tar pits of the skeletons for long extinct animals from the late Pleistocene era such as the saber-toothed tiger Smilodon californicus. However, one animal is beautifully adapted to the tarpits. Carnivorous larvae of the oil fly Helaeomyia petrolei swim happily in this viscous tar, and actually prefer high viscosity oils (Chopard, 1963), prompting Thorpe $(1930,1931)$ to refer to the oil fly as "undoubtedly one of the chief biological curiosities of the world." Oil fly larvae consume trapped carrion and the tar is ingested incidentally. We have observed tar filling the entire digestive tract with no adverse effect on the larvae. We then reasoned that any microbes in the larval gut would be of interest because they would perforce be petroleum/solvent resistant microbes. The novelty of this project was reinforced when a literature search revealed only one publication between the start of our own work (1994) and when the system had been described by Thorpe (1930, 1931). The present review describes our studies on the microbiology of oil fly larvae (Kadavy et al., 1999, 2000) as well as our retrospective on this work ten years later.

The La Brea tar pits are the best known of a series of natural oil seeps throughout Southern California. These oil seeps emerge from the ground amidst the grass and trees of a woodlands environment which is now mostly urban (Fig. 1). Oil seeps are visible around the tree in the foreground. For perspective, that's a leaf shown on the left of one of them (Fig. 2). Larvae live their entire lives submerged in pools of crude oil, but they occasionally need to surface to breathe (center of close up, Fig. 3). Larvae are typically $0.5^{-1.0} \mathrm{~mm}$ in diameter and 5-12 $\mathrm{mm}$ in length (Kadavy et al., 1999). Mature larvae leave the oil to pupate on nearby dry debris and vegetation (Hogue, 1993), producing small black gnat-like flies which are about $1.5 \mathrm{~mm}$ long (Fig. 4).

\section{What's There?}

We collected larvae from 3 seeps within the La Brea tar pits (more properly called the Rancho La Brea asphalt seeps) on 5 occasions between 1994 and 1997 (Kadavy et al., 1999). The viscous black oil was removed and the larvae were surface sterilized by washing in 60\% linoleic acid (5x) followed by 70\% ethanol (2X), 15\% hypochlorite 


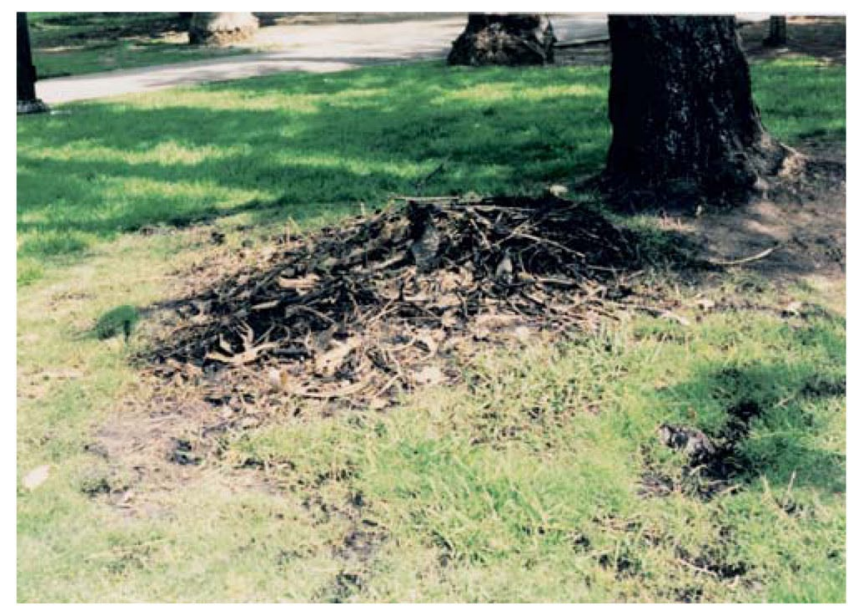

Figure 1 A typical oil seep at La Brea.

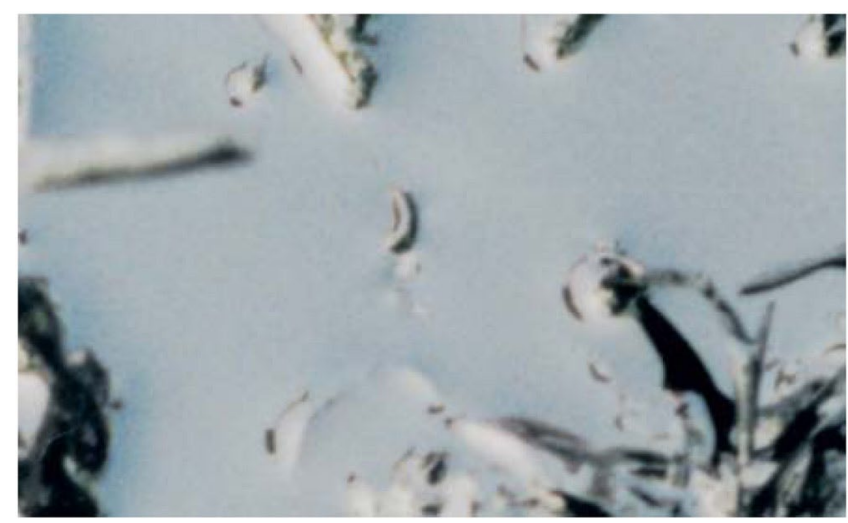

Figure 3 Larva surfacing in pool of crude oil.

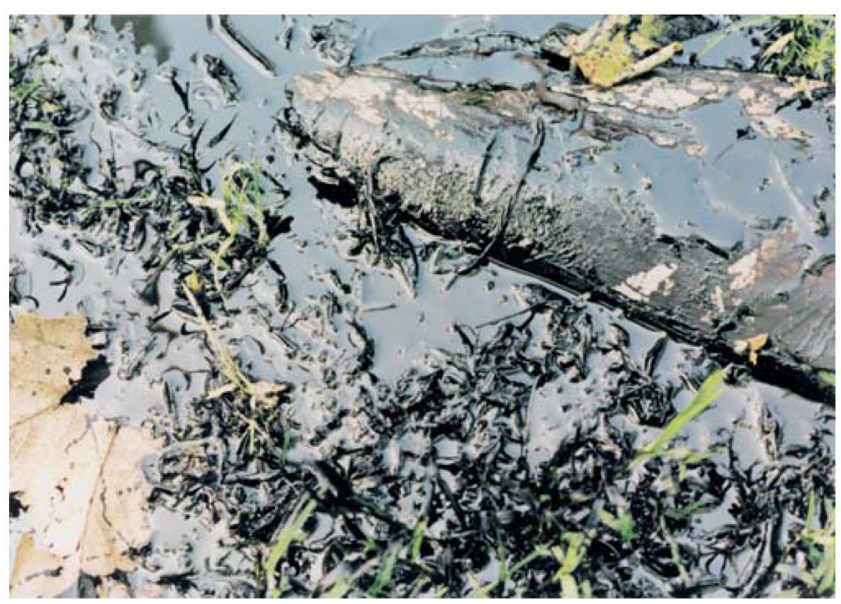

Figure 2 Oil pool

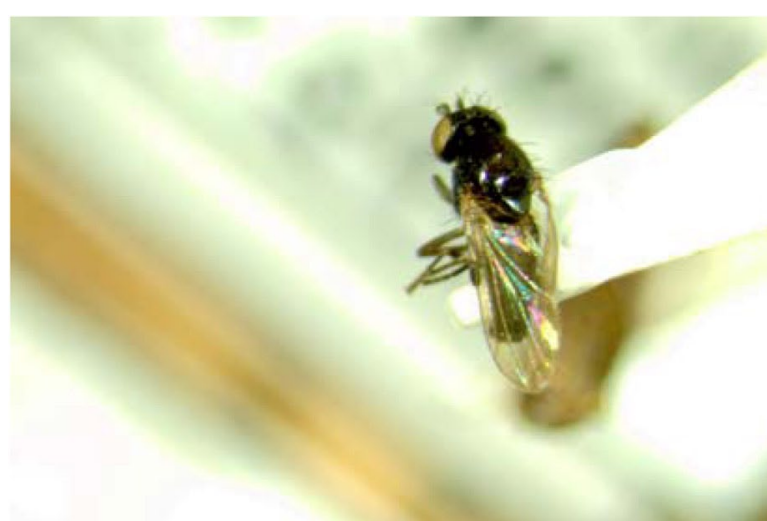

Figure 4 Adult oil fly.

containing $0.1 \%$ Tween 20, and phosphate buffered saline (PBS) containing $0.1 \%$ Tween $20(2 \mathrm{X})$. Active larvae were then allowed to crawl on the surface of LB agar plates to prove that they had been surface sterilized.

The larvae were translucent, allowing for direct observation of the oil within the digestive tract, and weighed ca. $3.3 \mathrm{mg}$ each. Their gut system occupied ca. $50 \%$ of the total larval volume, no ceca were detected, and the gut pH was 6.5-6.6 (Kadavy et al., 1999). Homogenized larvae from three different sites collected over a period of 4 years contained $10^{5}$ to $10^{6} \mathrm{CFU}$ when incubated aerobically on YEPM, 
LB, or MacConkey agar plates. They averaged $2 \times 10^{5}$ heterotrophs per larva. For one set of larvae, acridine orange direct count analysis indicated $8.6 \times 10^{5}$ total microbes per larva, corresponding to $1.4 \times 10^{5}$ CFU per larva for that set. Thus, $16 \%$ of the total microbial population was culturable on these rich plates; a percent culturable value comparatively high for environmental samples. Rich media were chosen for plating because oil fly larvae are carnivorous; they do not survive on oil/tar alone. To illustrate this point, larvae swarmed to egg meat medium (Difco) or beef liver which were required to sustain the larvae in the lab. Without these nutrients, the larvae would expire within one-week of collecting.

No endospore forming (heat resistant) bacteria were detected under aerobic culture conditions and no fungi were found. Approximately $1 \%$ of the culturable bacteria were nitrogen-fixing bacteria. We assumed that these nitrogen-fixing bacteria were among the enteric bacteria detected but this point was never proven. When these isolation procedures were repeated under anaerobic conditions, very few (S100) CFU were found. Two of these anaerobic colonies were later identified as Enterococcus faecalis and Clostridium sporogenes (Kadavy, 2001).

The numbers of bacteria detected address the question of whether those bacteria reside in the larval gut or are merely transient. The bacteria clearly grow in the larval gut because, on a per weight basis, the number of bacteria in the larval guts was always 100 to 1,000 times more CFU than in the oil being ingested. These calculations are relevant because repeated cycling of oil through the larval gut results in substantially increased CFU in the oil. This point is nicely illustrated by comparing the counts found in newly emerged asphalt with no insects (30 CFUmg-1), older asphalt containing many insects $\left(600 \mathrm{CFUmg}^{-1}\right.$ ), and the oil in which the larvae had been swimming just prior to surface sterilization $\left(5,500 \mathrm{CFUmg}^{-1}\right)$.

\section{Who's There?}

Which bacteria are present? Bacteria from the July 1997 collection were plated on LB, MacConkey, and blood agar plates. From 4,532 total colonies, eight different colony morphologies were recognized. After $24 \mathrm{~h}$ at $37^{\circ} \mathrm{C}$, roughly $70 \%$ of the colonies were $2-4 \mathrm{~mm}$ in diameter whereas the remaining 30\% were translucent, pinpoint colonies. All 
stained as Gram negative bacteria. Fourteen representative colonies were picked for identification by the Enterotube II system (BBL), API 20E strips (bio Merieux Vitek Inc.), and fatty acid profiles (MIDI Labs, Newark, DE). These isolates were called OFoo1 through OFo14. Nine of the 14 isolates were identified as Providencia rettgeri by 2 or more tests, although a Proteus sp. often seemed like a statistically close second choice. These bacteria were not clonal in that the Enterotube and API identifications found 5 or 6 different metabolic profiles, respectively, for bacteria designated $P$. rettgeri. The $P$. rettgeri/Proteus $s p$. identifications were all among the larger 2-4 mm colonies. The pinpoint colonies were all identified as Acinetobacter sp or as Shewanella putrefaciens. However, even though $P$. rettgeri and Acinetobacter sp were the dominant bacteria in the 1997 samples, fatty acid profiles of the dominant colony morphologies from 1994 identified Enterobacter sp, Hafnia alvei, and Acinetobacter radioresistens (Kadavy et al., 1999). Moreover, the isolates we cultured from the larval guts do not align with the diversity of organisms subsequently identified in and around active tar pits by Kim and Crowley (2007). They cultured 235 bacteria and archaea from two La Brea pits being excavated for fossil remains. The lack of overlap between these two tar/asphalt related populations further illustrates the uniqueness of the larval gut as a microbial habitat.

\section{Bioremediation}

We live in a world increasingly burdened by chemical pollutants. These are often complex aromatic hydrocarbons found in solvent or detergent rich environments. The composition of the La Brea tar is highly weathered; few linear alkanes remain. Thin layer chromatography (TLC) analysis showed that the La Brea tar is composed of 10\% branched alkanes and alkylated cyclic alkanes, $47 \%$ aromatics, 30\% resins, and 13\% polars, while GC/MS analysis showed significant hopanes, phenanthrene, and C1-, C2-, and C3-phenanthrenes. These previously unpublished analyses were kindly provided by Roger C. Prince, ExxonMobil, Annandale, New Jersey. What would be more natural than finding polyaromatic hydrocarbon degrading bacteria in the guts of oil fly larvae which are continuously ingesting tar/asphalt estimated to be $47 \%$ aromatic? However, for both the 1994 and 1997 
collections, we did not find any bacteria able to grow on benzene, toluene, naphthalene, anthracene, phenanthrene, chrysene, benzopyrene, or camphor as the sole source of carbon and energy (Kadavy et al., 1999). However, ca. 40\% of the 1994 isolates were able to grow on short-chain linear alkanes such as dodecane and most of the 1997 isolates were able to grow on hexane. The tests for possible degradation of aromatic compounds were conducted in the basal medium of Stanier et al. (1966) so it is unlikely that the absence of growth was due to an unfulfilled metal or vitamin requirement. At that time, none of the tests were done under co-culture or co-metabolism conditions, or with the Acinetobacter sp isolates which might have been more attractive candidates. As an example, we made several attempts to enrich for target microbes capable of mineralizing or being tolerant to aromatic solvents such as benzene or toluene, from both the insect guts and the oil seeps. Typically, the enrichment flasks became turbid, indicating growth, but that growth could not be sustained over multiple transfers into fresh, solvent saturated media. Moreover, the isolates recovered from those initial enrichment flasks did not display increased tolerance to aromatic solvents (Plantz, unpublished data).

\section{Solvent Tolerance}

The effux pumps of gram-negative bacteria expel a remarkably broad range of antimicrobial compounds, including antibiotics, detergents, dyes, and organic solvents. The linkage between antibiotic resistance and solvent tolerance in $P$. rettgeri is nicely shown by comparing the abilities of oil fly bacteria to survive solvent overlays with and without prior exposure to tetracycline. Cell survival was dramatically enhanced by prior incubation with $20 \mu \mathrm{g}$ of tetracycline per $\mathrm{ml}$ (Kadavy, 2001). With tetracycline present, seven of the nine isolates tolerated $100 \%$ cyclohexane, six tolerated benzene-cyclohexane and toluene-cyclohexane (both 1:9), and three tolerated xylene-cyclohexane (1:1).

Probably of greater industrial significance would be the production of solvent tolerant extracellular enzymes. Isolates OFoo7, OFO10, and OFO11 were selected for further study. Remember that these bacteria make their living by degrading whatever was ingested by the carnivorous oil fly larvae, usually other insects, in a high asphalt gut 
environment. Our initial results were promising. For each strain, at least seven extracellular proteins were detected as bands by SDS-PAGE or as peaks off a Sephadex G-150 column. We then examined enzyme activities by incorporating 9 turbid polymers into agar plates and looking for zones of clearing around the respective colonies. These strains of $P$. rettgeri lysed red blood cells and produced extracellular DNAse and coagulase but, surprisingly, we did not detect any proteases (on either gelatin or casein), chitinases, keratinases, lipases, or amylases (Kadavy, 2001). The extracellular proteins were not studied further.

\section{Antibiotic Resistance}

Twelve of the 14 OF cultures, including all 9 of those identified as $P$. rettgeri, were tested to determine their sensitivity or resistance to paper discs containing 23 common antibiotics (Kadavy et al., 2000). The levels and frequency of antibiotic resistance were remarkable. All 9 of the $P$. rettgeri strains were highly resistant to tetracycline, vancomycin, bacitracin, erythromycin, novobiocin, polymyxin, rifampin, colistin, and nitrofurantoin, while eight of the nine were highly resistant to spectinomycin. In contrast, the $P$. rettgeri strains were highly sensitive to nalidixic acid, streptomycin, norfloxacin, aztreonam, ampicillin, ciprofloxacin, cefoxitin, cefotaxime, and piperacillin, and somewhat sensitive to kanamycin and tobramycin (Kadavy et al., 2000).

Have we identified the evolutionary origin of antibiotic resistance in bacteria? The linkage between antibiotic resistance and aromatic hydrocarbons becomes obvious when one considers that tetracycline is structurally related to the polyaromatic hydrocarbons. The La Brea asphalt seeps are at least 40,000 years old and most of the antibiotics to which our $P$. rettgeri isolates were resistant are hydrophobic molecules containing aromatic ring systems. Thus, we suggested that the oil fly bacteria and their genes for solvent tolerance provide a microbial reservoir of antibiotic resistance genes, i.e., the survival of $P$. rettgeri in the La Brea asphalt seeps depends on the ability of the cells to pump out these aromatic and polyaromatic hydrocarbons. This line of thought, which presupposes that our oil fly bacteria have never been subjected to antibiotic stress, reinforces earlier suggestions on the possible overlap between antibiotics and xenobiotics (Blasco et al., 1995). 


\section{Insect-Microbe Interactions}

Is the relation between oil fly bacteria and oil fly larvae symbiotic, mutualistic, or mere coincidence? The limitation here is in the insect life cycle. Oil fly larvae (Fig. 3) are available but adult insects (Fig. 4) and eggs are not; there are no established colonies of oil flies. The eggs would, of course, be needed to obtain germ free insects for study. At present the evidence suggests a mutual relationship whereby the bacteria gain a protected environment high in water, nitrogen, and phosphorous while the insects gain a detoxification system and, more tentatively, the ability to extract nutrients from the oil. Chopard (1963) suggested that bacteria might assist larvae to gain energy from the paraffin fraction, even though we now know that most of the paraffins have been lost due to weathering. His view was based in part on the observation that gut petroleum appears to stay restricted within the chitinous peritrophic membrane. Similarly, the evidence for detoxification is mostly visual. As the bolus of tar passes through the larval gut, it goes from being a black and viscous tar to something having the appearance of motor oil. This change suggests that the tar has been transformed, but we have no idea into what. Clearly the insects cannot live on oil alone, and we were unable to identify any polyaromatic hydrocarbon degrading bacteria among either the 1994 or 1997 collections. These studies should be revisited, giving particular attention to possible consortia of microorganisms that could not be sustained under the laboratory conditions originally chosen, as well as to potential resin and asphaltene degrading bacteria. This line of thought suggests that insect associated microbes should constitute a fertile hunting ground in the search for novel microbes. This viewpoint was a cornerstone in the rationale for establishing the Invertebrate Microbiology section of Applied \& Environmental Microbiology.

\section{Global Impact}

The worldwide distribution of oil flies is not yet clear. Published reports indicate that oil flies are restricted to oil pools and natural oil seeps in Southern California, Cuba, and Trinidad (Foote, 1995; Hogue, 1993; Thorpe, 1931) although anecdotal evidence suggests that they are far more widespread. At this point, oil flies and the microbes in 
their digestive tracts remain as biological curiosities, and a tantalizing but untapped source of potentially useful hydrocarbon transforming bacteria and hydrocarbon/solvent tolerant enzymes. But, if our antibiotic resistance hypothesis is true, the medical impact of our findings might be more significant. Acinetobacter baumannii is an opportunistic human pathogen and a frequent cause of nosocomial outbreaks (Richet and Fournier, 2006). It is often multi-drug resistant (MDR). The Centers for Disease Control and the Walter Reed Army Medical Center recently high- lighted the enormity and gravity of MDR A. baumannii infections in military medical facilities treating personnel injured in Iraq and Kuwait (Hujer et al., 2006). Another recent study examined 20 isolates of MDR A. baumannii from nosocomial outbreaks in Los Angeles (Valentine et al., 2008). This juxtaposition suggests that the epidemic potential of MDR in A. baumannii may be related to Acinetobacter having first adapted to life in PAH-enriched environments such as the La Brea tar pits and oil laden sands.

\section{Research Needs}

What would we have done differently? What needs to be done now? What can we do now that couldn't have been done 10 years ago?

1. We should revisit the question of which bacteria are oil fly associated using modern 16S rRNA gene sequencing. Thus, we could find out if our previous identifications of Providencia/Proteus and Acinetobacter were an accurate sampling of the bacteria present. This knowledge might also drive improvements in the culture techniques chosen. We could also explore seasonal variations in the bacterial populations as well as variations among individual larvae. For instance, Southern California has distinct seasonal rainfall rates, a wet and dry season, during which water content surrounding the seeps will vary and may influence the microbial species present.

2. Focus on the Acinetobacters. Our earlier selection and growth conditions were optimized for enteric bacteria, not for hydrocarbon metabolizing Acinetobacters. These growth and selection procedures need to be improved. The genus Acinetobacter is the 
best-known representative of the alkane-degrading a-Proteobacteria and alkane degradation seems to be a common property of most Acinetobacter strains (Baumann et al., 1968). Also, many bioemulsifiers are produced by the genus Acinetobacter (McInerney et al., 2005), while a high percentage of the oil fly bacteria we studied also produced surfactants (Kadavy, 2001).

3. Heavy Petroleum. We know that La Brea tar enters the larval mouth in a dark viscous state and exits as something close to motor oil. This transition should be followed by GC/MS analysis of the contents as they progress through the gut. In light of the recent economic push to recover heavy petroleum from underground sources, a consortium of larval gut microbes could be found to reduce the viscosity of the heavy petroleum and allow for easier removal push to recover heavy petroleum from underground sources, a consortium of larval gut microbes could be found to reduce the viscosity of the heavy petroleum and allow for easier removal.

4. Functional Metagenomics. Knowledge of the genes associated with hydrocarbon mineralization has grown significantly in the 14 years since we initiated this research, as has the ability to sequence DNA. Metagenomics of the larval gut and the surrounding environ- mental communities would quickly identify if the potential for hydrocarbon mineralization is present within these microbial communities. This approach would also provide a better chance of isolating novel solvent-tolerant bacteria making useful solventtolerant enzymes.

\section{References}

Baumann P, Doudoroff M, Stanier RY (1968) A study of the Moraxella group. II. Oxidative-negative species (genus Acinetobacter). J Bacteriol 95: 1520-1541.

Blasco R, Wittich R-M, Mallavarapu M, Timmis KN, Pieper DH (1995) From xenobiotic to antibiotic, formation of protoanemonin from 4-chlorocatechol by enzymes of the 3-oxoadipate pathway. J Biol Chem 270: 29229-29235.

Chopard L (1963) La mouche du petrole et les questions qu'elle pose. La Nature (Paris) 3338: 255-256.

Foote BA (1995) Biology of shore flies. Annu Rev Entomol 40: 417-442.

Hogue CL (1993) Insects of the Los Angeles Basin, 2nd edn. Los Angeles: Natural History Museum of Los Angeles County. 
Hujer KM, Hujer AM, Hulten EA, Bajaksouzian S, Adams JM, Donskey CJ, Ecker DJ, Massire C, Eshoo MW, Sampath R, Thomson JM, Rather PN, Craft DW, Fishbain JT, Ewell AJ, Jacobs MR, Paterson DL, Bonomo RA (2006) Analysis of antibiotic resistance genes in multi-drug resistant Acinetobacter sp. Isolates from military and civilian patients treated at the Walter Reed Army Medical Center. Antimicrob Agents Chemother 50: 4114-4123.

Kadavy DR (2001) Characterization of microorganisms associated with Helaeomyia petrolei (oil fly) larvae. Ph.D. thesis, University of Nebraska, Lincoln.

Kadavy DR, Hornby JM, Haverkost T, Nickerson KW (2000) Natural antibiotic resistance of bacteria isolated from larvae of the oil fly, Helaeomyia petrolei. Appl Environ Microbiol 66: 4615-4619.

Kadavy DR, Plantz B, Shaw CA, Myatt J, Kokjohn TA, Nickerson KW (1999) Microbiology of the oil fly, Helaeomyia petrolei. Appl Environ Microbiol 65: 1477-1482.

Kim J-S, Crowley DE (2007) Microbial diversity in natural asphalts of the Rancho La Brea Tar Pits. Appl Environ Microbiol 73: 4579-4591.

McInerney MJ, Nagle DP, Knapp RM (2005) Microbially enhanced oil recovery: past, present, and future. In Petroleum Microbiology, B Ollivier, and M Magot (eds.). Washington: ASM Press, pp. 215-237.

Richet H, Fournier PE (2006) Nosocomial infections caused by Acinetobacter baumannii: a major threat worldwide. Infect Control Hosp Epidemiol 27: 645-646.

Stanier RY, Palleroni NJ, Doudoroff M (1966) The aerobic pseudomonads: a taxonomic study. J Gen Microbiol 43: 159-271.

Thorpe WH (1930) The biology of the petroleum fly (Psilopa petrolei). Trans Entomol Soc Lond 78: 331-344.

Thorpe WH (1931) The biology of the petroleum fly. Science 73: 101-103.

Valentine SC, Contreras D, Tan S, Real LJ, Chu S, Xu HH (2008) Phenotypic and molecular characterization of Acinetobacter baumannii clinical isolates from nosocomial outbreaks in Los Angeles county California. J Clin Microbiol 46: 2499-2507. 